\title{
Effect of Metal (Mn, Ti) Doping on NCA Cathode Materials for Lithium Ion Batteries
}

\author{
Dao Yong Wan $\mathbb{D}^{1},{ }^{1}$ Zhi Yu Fan $\mathbb{D}^{1},{ }^{1}$ Yong Xiang Dong $\mathbb{D}^{1},{ }^{1}$ Erdenebayar Baasanjav, ${ }^{1}$ \\ Hang-Bae Jun, ${ }^{1}$ Bo Jin $\left(\mathbb{D},{ }^{2}\right.$ En Mei Jin $\mathbb{D}^{\mathrm{D}},{ }^{1}$ and Sang Mun Jeong ${ }^{1}{ }^{1}$ \\ ${ }^{1}$ School of Environmental, Urban and Chemical Engineering, Chungbuk National University, 1 Chungdae-ro, Seowon-Gu, \\ Cheongju, Chungbuk 28644, Republic of Korea \\ ${ }^{2}$ Key Laboratory of Automobile Materials, Ministry of Education, College of Materials Science and Engineering, \\ Jilin University, Changchun 130022, China \\ Correspondence should be addressed to En Mei Jin; kujie@naver.com and Sang Mun Jeong; smjeong@chungbuk.ac.kr
}

Received 25 September 2017; Revised 5 December 2017; Accepted 24 December 2017; Published 30 January 2018

Academic Editor: Bhanu P. Singh

Copyright (C) 2018 Dao Yong Wan et al. This is an open access article distributed under the Creative Commons Attribution License, which permits unrestricted use, distribution, and reproduction in any medium, provided the original work is properly cited.

\begin{abstract}
NCA $\left(\mathrm{LiNi}_{0.85} \mathrm{Co}_{0.10} \mathrm{Al}_{0.05-x} \mathrm{M}_{x} \mathrm{O}_{2}, \mathrm{M}=\mathrm{Mn}\right.$ or $\left.\mathrm{Ti}, x<0.01\right)$ cathode materials are prepared by a hydrothermal reaction at $170^{\circ} \mathrm{C}$ and doped with $\mathrm{Mn}$ and $\mathrm{Ti}$ to improve their electrochemical properties. The crystalline phases and morphologies of various NCA cathode materials are characterized by XRD, FE-SEM, and particle size distribution analysis. The CV, EIS, and galvanostatic charge/discharge test are employed to determine the electrochemical properties of the cathode materials. Mn and Ti doping resulted in cell volume expansion. This larger volume also improved the electrochemical properties of the cathode materials because $\mathrm{Mn}^{4+}$ and $\mathrm{Ti}^{4+}$ were introduced into the octahedral lattice space occupied by the Li-ions to expand the Li layer spacing and, thereby, improved the lithium diffusion kinetics. As a result, the NCA-Ti electrode exhibited superior performance with a high discharge capacity of $179.6 \mathrm{mAh} \mathrm{g}^{-1}$ after the first cycle, almost $23 \mathrm{mAh} \mathrm{g}^{-1}$ higher than that obtained with the undoped NCA electrode, and $166.7 \mathrm{mAh} \mathrm{g}^{-1}$ after 30 cycles. A good coulombic efficiency of $88.6 \%$ for the NCA-Ti electrode is observed based on calculations in the first charge and discharge capacities. In addition, the NCA-Ti cathode material exhibited the best cycling stability of $93 \%$ up to 30 cycles.
\end{abstract}

\section{Introduction}

Currently, there is an increasing consumer demand for Liion batteries (LIBs) with long life, high energy, and high power density. LIBs can be used in many devices, from portable electronics to electric vehicles. However, there are many issues that need to be addressed when using LIBs in electric vehicles, including those related to cost, safety, and energy density considerations $[1,2]$.

Recently, transition metal-layered oxide $\mathrm{LiMO}_{2}(\mathrm{M}=\mathrm{Ni}$, $\mathrm{Mn}, \mathrm{Co}$ ) materials have generated interest as suitable solutions to the aforementioned issues, including specific capacity, energy density, safety, and cost [3, 4]. Among these materials, $\mathrm{LiNiO}_{2}$ is of low cost, has a large theoretical capacity $\left(275 \mathrm{mAh} \mathrm{g}^{-1}\right)$, and is more environmentally friendly than $\mathrm{LiCoO}_{2}$ [5-8]. However, several limitations such as a difficult synthesis protocol for stoichiometric $\mathrm{LiNiO}_{2}$, partially reversible phase for $\mathrm{LiNiO}_{2}$, and $\mathrm{Li} / \mathrm{Ni}$ cation mixing have to be overcome before $\mathrm{LiNiO}_{2}$ can be commercially used as a cathode material for LIBs. To resolve these issues, different metals such as $\mathrm{Co}, \mathrm{Al}$, and Fe were studied as dopants/partial substitutes for $\mathrm{Ni}$, which demonstrated promising but limited performance. Among these, Co and $\mathrm{Al}$ codoped $\mathrm{LiNi}_{1-x-y} \mathrm{Co}_{x} \mathrm{Al}_{y} \mathrm{O}_{2}(\mathrm{NCA}, 0.05 \leq x \leq 0.15$, $0.01 \leq y \leq 0.10)$ cathode materials exhibit the improved electrochemical properties and the thermal safety because cation substitution of $\mathrm{Co}$ and $\mathrm{Al}$ increases the stability of the structure $[5,9]$. However, a few drawbacks such as degradation during charge-discharge cycles and thermal runaway are yet to be resolved. Moreover, higher Ni concentrations result in highly unstable $\mathrm{Ni}^{3+}$ and $\mathrm{Ni}^{4+}$ ions remaining in the layered structure, and their reaction with the electrolyte speeds up 
degradation of the materials and batteries [10, 11]. In order to solve these problems, the small amounts of dopants at the cationic sites have been considered; for example, it has been reported that the addition of small amounts of $\mathrm{Cl}, \mathrm{Mg}, \mathrm{F}$, and $\mathrm{Na}$ improves the capacity and cycle performance [12-17].

In this work, the NCA cathode material was prepared by one step of hydrothermal reaction at $170^{\circ} \mathrm{C}$ and doped with either $\mathrm{Mn}$ or Ti. This is because $\mathrm{Mn}$ and $\mathrm{Ti}$ have similar atomic radii as that of $\mathrm{Ni}$ and, in coordination with oxygen, can replace the transition metal atoms in the octahedral interstitial sites. The aforesaid process enhances thermal and structural stability and, in some cases, decreases electronic and/or ionic resistance $[18,19]$. Herein, we report the effects of Mn or Ti doping on the crystalline structure and electrochemical properties of NCA.

\section{Experimental}

The NCA cathode materials were prepared via one step of hydrothermal reaction. First, $0.85 \mathrm{M}$ of nickel(II) sulfate hexahydrate $\left(\mathrm{NiSO}_{4} \cdot 6 \mathrm{H}_{2} \mathrm{O}, 99 \%\right.$, Sigma-Aldrich) and $0.15 \mathrm{M}$ of cobalt(II) sulfate heptahydrate $\left(\mathrm{CoSO}_{4} \cdot 7 \mathrm{H}_{2} \mathrm{O}, \geq 99 \%\right.$, SigmaAldrich) were dissolved in $2.5 \mathrm{M}$ of $\mathrm{NaOH}$ solution. After stirring vigorously for $1 \mathrm{~h}, 0.05 \mathrm{M}$ of aluminum hydroxide hexahydrate $\left(\mathrm{Al}(\mathrm{OH})_{3} \cdot 6 \mathrm{H}_{2} \mathrm{O}, 98 \%\right.$, Sigma-Aldrich) and ammonia solution were added sequentially, and the mixture was stirred for another half hour. Then, the resultant solution was transferred to a $100-\mathrm{mL}$ Teflon-lined stainless-steel autoclave, which was placed in a laboratory electric oven and heated at $170^{\circ} \mathrm{C}$, for $18 \mathrm{~h}$. After the hydrothermal reaction, the autoclave was cooled to room temperature. The obtained dark-green $\mathrm{Ni}_{0.85} \mathrm{Co}_{0.10} \mathrm{Al}_{0.05}(\mathrm{OH})_{2}$ powder was washed with deionized water and ethanol and centrifuged several times, followed by vacuum drying overnight at $120^{\circ} \mathrm{C}$. Next, the $\mathrm{Ni}_{0.85} \mathrm{Co}_{0.10} \mathrm{Al}_{0.05}(\mathrm{OH})_{2}$ powder was calcined at $500^{\circ} \mathrm{C}$ for $5 \mathrm{~h}$ in air to obtain $\mathrm{Ni}_{0.85} \mathrm{Co}_{0.10} \mathrm{Al}_{0.05} \mathrm{O}_{2}$, which was mixed with lithium hydroxide $\left(\mathrm{LiOH} \cdot \mathrm{H}_{2} \mathrm{O}, 99 \%\right.$, Sigma-Aldrich) in a molar ratio of $1: 1.05$ by hand grinding, and then, the mixture was calcined again at $700^{\circ} \mathrm{C}$ for $10 \mathrm{~h}$ under an $\mathrm{O}_{2}$ atmosphere $\left(\mathrm{O}_{2}\right.$ flow: $3 \mathrm{~mL} \mathrm{~min}^{-1}$ ) to obtain the $\mathrm{Li}_{1.05} \mathrm{Ni}_{0.85} \mathrm{Co}_{0.10} \mathrm{Al}_{0.05} \mathrm{O}_{2}$ (NCA) cathode material. The NCA cathode materials were doped with $\mathrm{Mn}$ and Ti to improve their electrochemical properties. For the metal-doping process, $0.01 \mathrm{~mol}$ of titanium (IV) isopropoxide $\left(\mathrm{C}_{12} \mathrm{H}_{28} \mathrm{O}_{4} \mathrm{Ti}, \geq 97 \%\right.$, Aldrich) or $0.01 \mathrm{~mol}$ of manganese(II) sulfate monohydrate $\left(\mathrm{MnSO}_{4} \cdot \mathrm{H}_{2} \mathrm{O}, 98 \%\right.$, Samchun) was added during the addition of the Al source. The obtained pristine NCA and Mn- and Ti-doped NCA cathode materials were denoted as NCA, NCA-Mn, and NCA-Ti, respectively.

For electrode fabrication, the cathode material (asprepared NCA, NCA-Mn, or NCA-Ti), super-p carbon black, and polyvinylidene fluoride (PVdF, $M_{w}: \sim 400000$, SigmaAldrich) in the weight ratio of $94: 3: 3$ were ground with $N$ methyl-2-pyrrolidone (NMP, Samchun Pure Chemical) as a solvent. The slurry was coated on $\mathrm{Al}$ foil by doctor blade method, and then, the electrode was dried for $1 \mathrm{~h}$ at $80^{\circ} \mathrm{C}$. The coated electrode was $20 \mu \mathrm{m}$ thick and it was pressed to $80 \%$ of the coating thickness. After drying under vacuum at $110^{\circ} \mathrm{C}$ for $24 \mathrm{~h}$, the electrode was cut into a round plate

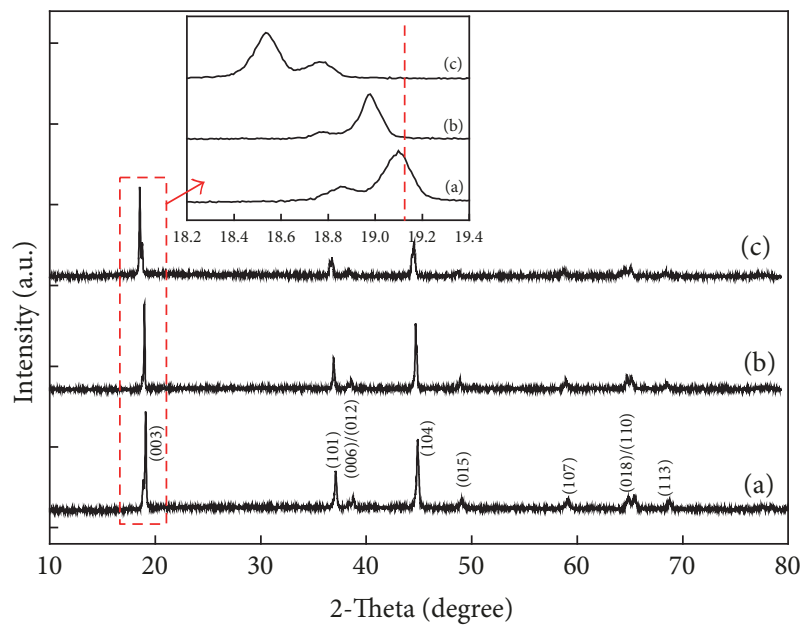

FIGURE 1: XRD patterns of (a) NCA, (b) NCA-Mn, and (c) NCA-Ti powders.

$(\Phi=15.958 \mathrm{~mm})$. The CR2032 coin-type cell was assembled in an argon-filled glove box with oxygen and moisture levels $<1 \mathrm{ppm}$. Lithium foil, polyethylene (PE, W-SCOPE), and $1 \mathrm{M}$ $\mathrm{LiPF}_{6} / \mathrm{EC}-\mathrm{DMC}(3: 7, \mathrm{v} / \mathrm{v})$ were used as the counter electrode, separator, and electrolyte, respectively.

The crystalline phases of various NCA cathode materials were identified using X-ray diffraction (XRD, Dmax/1200, Rigaku) using $\mathrm{CuK} \alpha$ radiation $(\lambda=1.5406 \mathrm{~nm}, 40 \mathrm{kV}, 40 \mathrm{~mA})$ over the range $2 \theta=10-80^{\circ}$. The morphologies of various NCA cathode materials were characterized by field-emissionscanning electron microscopy (FE-SEM, LEO-1530, Carl Zeiss). The electrical conductivities and particle size distribution of the NCA cathode materials were analyzed by a powder resistivity measurement system (HPRM-M2, HAN TECH) and a particle size analyzer (Mastersizer 3000, Marvern). Cyclic voltammetry was carried out in an automated charge-discharge equipment (WBCS 3000L, WonATech) at a scanning rate of $0.1 \mathrm{mV} \mathrm{s}^{-1}$ in the voltage range $2.8-4.5 \mathrm{~V}$. The charge-discharge test (WonATech, WBCS 3000L) was performed at potentials ranging from 3.0 to $4.3 \mathrm{~V}$ at $0.1 \mathrm{C}$. The electrochemical impedance measurements were performed using electrochemical impedance spectroscopy (EIS, PGSTAT302N, Metrohm Autolab B.V.) in the frequency range $0.01-100 \mathrm{kHz}$ at an amplitude of $10 \mathrm{mV}$. All electrochemical measurements were performed at $25^{\circ} \mathrm{C}$.

\section{Results and Discussion}

Figure 1 shows the XRD patterns of pristine NCA, NCA-Mn, and NCA-Ti powders in the $2 \theta$ range $10-80^{\circ}$. All the peaks can be indexed to a hexagonal $\alpha-\mathrm{NaFeO}_{2}$ structure (space group, $R \overline{3} \mathrm{~m})$. The sharp and intense peaks at $18.8^{\circ}, 36.7^{\circ}, 44.5^{\circ}, 48.2^{\circ}$, and $58.3^{\circ}$ were representative of the (003), (101), (104), (015), and (107) diffraction planes, respectively [20]. Furthermore, the splitting of the two peaks $(006) /(102)$ and $(108) /(110)$ was observed clearly at $37.7-38.7^{\circ}$ and $63.6-65.4^{\circ}$, respectively, confirming that a typical layered structure formed in the 


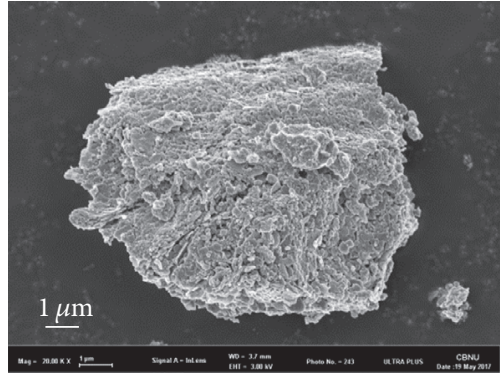

(a)

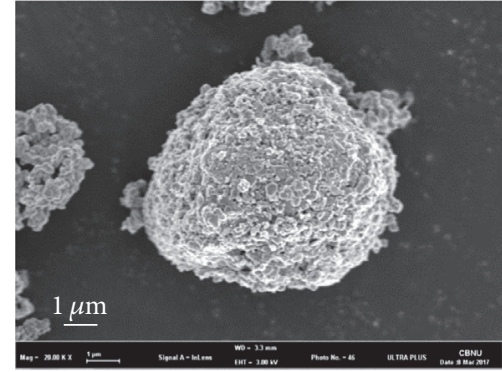

(b)

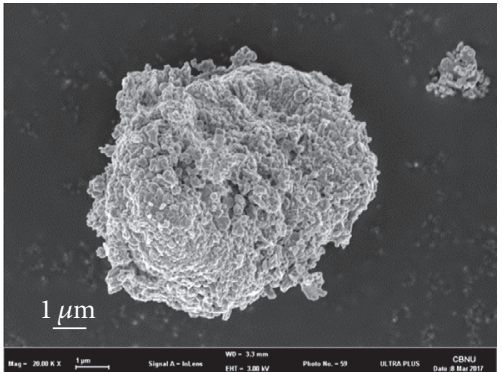

(c)

Figure 2: FE-SEM images of (a) NCA, (b) NCA-Mn, and (c) NCA-Ti powders.

TABLE 1: Lattice parameters of the NCA, NCA-Mn, and NCA-Ti powders.

\begin{tabular}{lccccc}
\hline Samples & $a(\AA)$ & $c(\AA)$ & $V\left(\AA^{3}\right)$ & $c / a$ & $I_{003} / I_{104}$ \\
\hline NCA & 2.8674 & 14.0433 & 99.9999 & 4.8976 & 1.4708 \\
NCA-Mn & 2.8705 & 14.1362 & 100.8809 & 4.9246 & 1.6331 \\
NCA-Ti & 2.8727 & 14.2648 & 101.9534 & 4.9656 \\
\hline
\end{tabular}

crystal lattice [21]. In particular, the (003) peak of NCA$\mathrm{Mn}$ and NCA-Ti shifted slightly toward the lower-angle region (inset of Figure 2) because $\mathrm{Mn}^{4+}$ and $\mathrm{Ti}^{4+}$ ions were introduced into the octahedral lattice space occupied by the Li-ions to expand the Li layer spacing and, thereby, improve the lithium diffusion kinetics [22]. The variations in the lattice parameters were calculated by the Rietveld refinement method; the results are provided in Table 1 . The integrated intensity ratio $I_{(003)} / I_{(104)}$ has been used as an indicator of $\mathrm{Li}^{+} / \mathrm{Ni}^{2+}$ cation mixing $\left(\mathrm{Ni}^{2+}\right.$ at the $3 \mathrm{a}$ site and $\mathrm{Li}^{+}$at the $3 \mathrm{~b}$ site in the space group $R \overline{3} \mathrm{~m}$ ): values smaller than 1.3 indicate a high degree of cation mixing because of the presence of other ions in the lithium interslab region. Thus, the reversible capacity of the cathode material tends to decrease when the ratio is $<1.2$ [23-27]. As shown in Table 1 , the $I_{(003)} / I_{(104)}$ diffraction peaks are higher for NCA-Ti, which could be greatly affected by the presence of Ti-metal ions in the lithium layer, thus leading to better electrochemical properties.

The typical morphology of the NCA, NCA-Mn, and NCA-Ti powders is shown in Figure 2. Here, the small primary particles are organized into larger agglomerates as secondary particles. These three NCA cathode materials comprise almost spherical particles.

To investigate the doping results, element mapping and energy dispersive X-ray spectrometry (EDS) analyses were performed on the NCA, NCA-Mn, and NCA-Ti cathode materials. Figure 3 shows the $\mathrm{Al}, \mathrm{Co}, \mathrm{Ni}, \mathrm{Mn}$, and $\mathrm{Ti}$ element mapping results for NCA (Figure 3(a)), NCA-Mn (Figure 3(b)), and NCA-Ti (Figure 3(c)). The signals from Mn and $\mathrm{Ti}$ (bright yellow and green spots, respectively) clearly demonstrate that $\mathrm{Mn}$ and Ti were homogeneously distributed throughout the NCA-Mn and NCA-Ti particles. The Mn and Ti contents in the NCA cathode materials were analyzed by EDS. The weight percent of $\mathrm{Mn}$ and $\mathrm{Ti}$ was $0.8385 \%$ and $0.7049 \%$, and their atomic percent was $0.8557 \%$ and $0.8529 \%$, respectively.
Figure 4(a) shows the particle size distribution of the NCA, NCA-Mn, and NCA-Ti powders. As shown in Figure 4, three kinds of powders exhibited a bimodal distribution of particle sizes such as with small particle distribution at $3-5 \mu \mathrm{m}$ and large particle at $10-30 \mu \mathrm{m}$. The NCA powder has an almost 1:1 volume density of small and large particle; however, the large range $(10-30 \mu \mathrm{m})$ of volume density was increased after doping of $\mathrm{Mn}$ or Ti into the NCA. In results, the NCA-Mn has a higher volume density of large particle size than others. The electrical conductivities of the NCA, NCA$\mathrm{Mn}$, and NCA-Ti powders were measured, and the results are depicted in Figure 4(b). The electrical conductivity $(\sigma)$ was measured at room temperature in the compression pressure range 5-23 $\mathrm{MPa}$. The sample weight of the powder was approximately $1.0 \mathrm{~g}$, and the diameter of the measuring die was $1.1 \mathrm{~cm}$. The electrical conductivity was determined by the equation $\sigma=h /(R \cdot A)$, where $R$ is the electrical resistance $(\Omega)$, $A$ is the area of the pellet surface $\left(\mathrm{m}^{2}\right)$, and $h$ is the distance (m) from the bottom to the top of the sample. As shown in Figure 4(b), an increase in pressure increases the electrical conductivity for all the cathode materials considered in this study. The electrical conductivity of the metal-doped NCA powder exceeds that of pristine NCA under all pressure conditions, possibly because of the metal ions in the lithium layer. The electrical conductivities of the NCA, NCA-Mn, and NCA-Ti powders at $10 \mathrm{MPa}$ are $2.92,3.65$, and $3.62 \mathrm{~S} \mathrm{~m}^{-1}$, respectively.

The electrochemical properties of different NCA cathodes for LIBs were investigated by cyclic voltammetry (CV) using a coin-type cell with a potential window of $2.8-4.5 \mathrm{~V}$ at scan rate of $0.1 \mathrm{mV} \mathrm{s}^{-1}$, as shown in Figure 5. In the $\mathrm{CV}$ curve, the peak currents represent the electrochemical properties of the material and express the phase transitions that occur during the intercalation/deintercalation of lithium ions [28, 29]. During the charge and discharge process, three pairs of peaks can be observed (I-I', II-II', and III-III') in the CV 

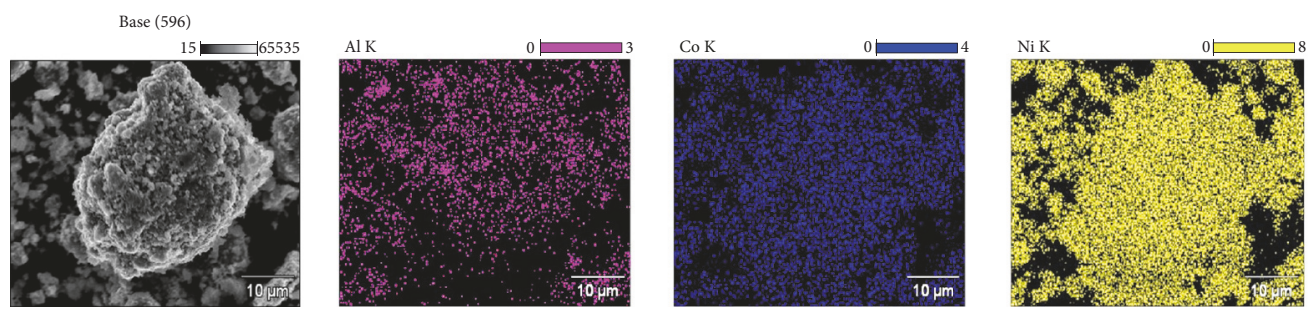

(a)
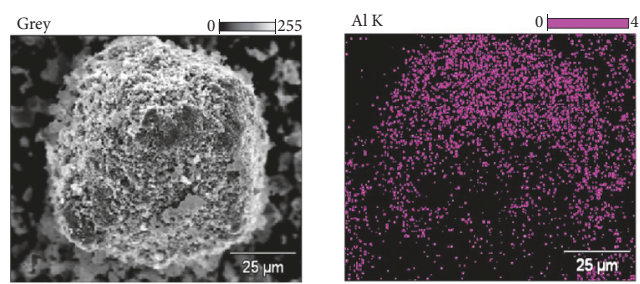

Base (589)
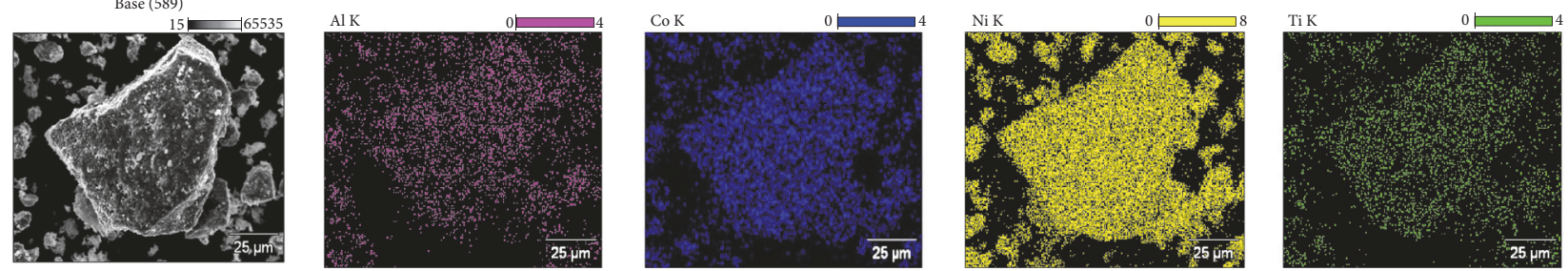

(c)

FIGURE 3: EDS elemental mapping of (a) NCA, (b) NCA-Mn, and (c) NCA-Ti powders.

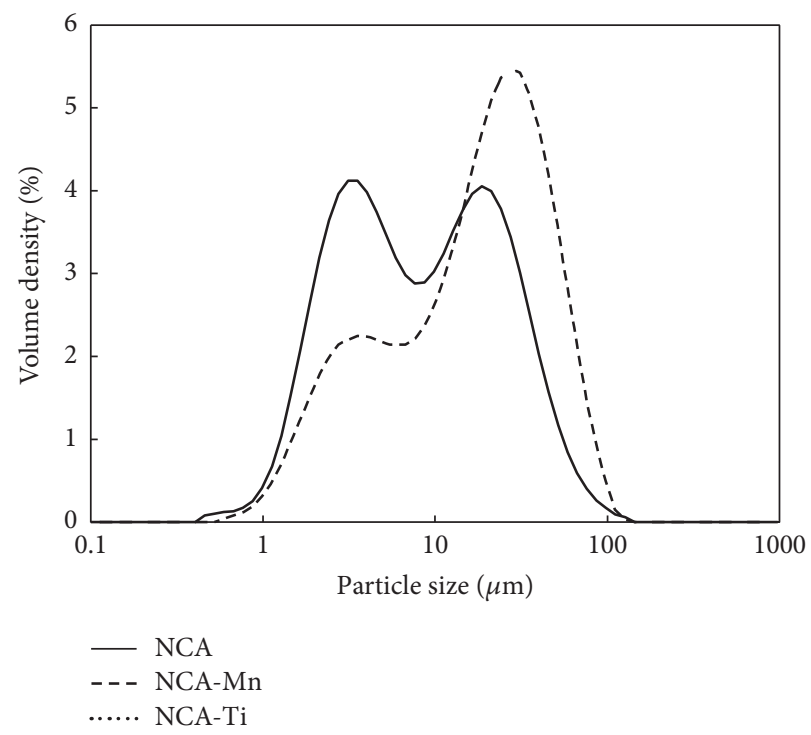

(a)

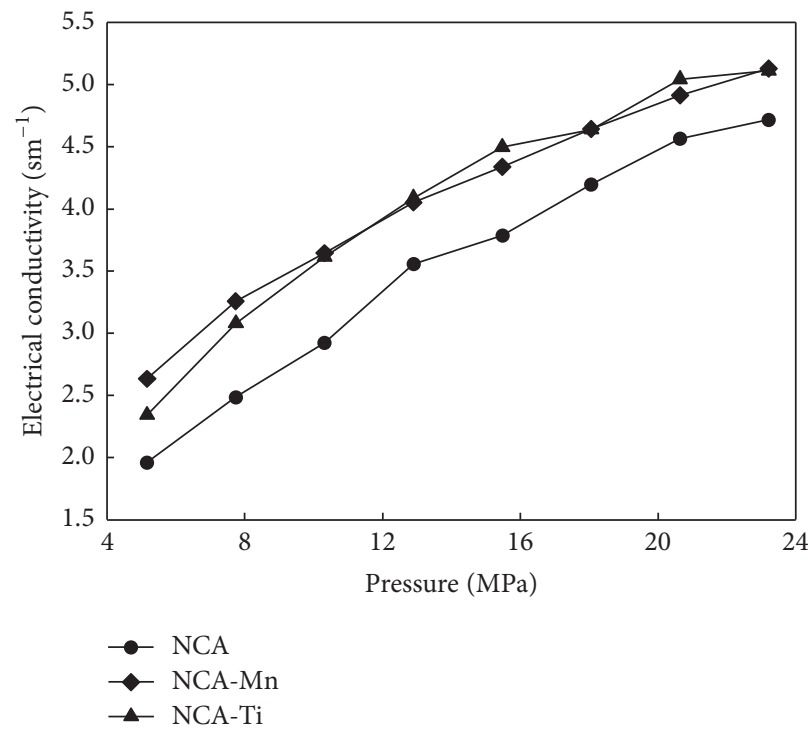

(b)

Figure 4: (a) Particle size distribution and (b) electrical conductivity with applied pressure for NCA, NCA-Mn, and NCA-Ti powders.

diagram, which are attributed to hexagonal to monoclinic, monoclinic to hexagonal, and hexagonal to hexagonal phase transitions, respectively $[30,31]$ In the case of NCA, the oxidation peaks around 3.84, 4.02, and $4.20 \mathrm{~V}$ denote I, II, and III, respectively. The corresponding reduction peaks around
3.66, 3.93, and $4.12 \mathrm{~V}$ denote $\mathrm{I}^{\prime}, \mathrm{II}^{\prime}$, and III'. The NCA-Mn and NCA-Ti electrodes exhibit a broad oxidation peak with shoulders near 3.94 and $3.79 \mathrm{~V}$, respectively, which may result from the lower intensity of lithium clustering due to metal doping [30]. 

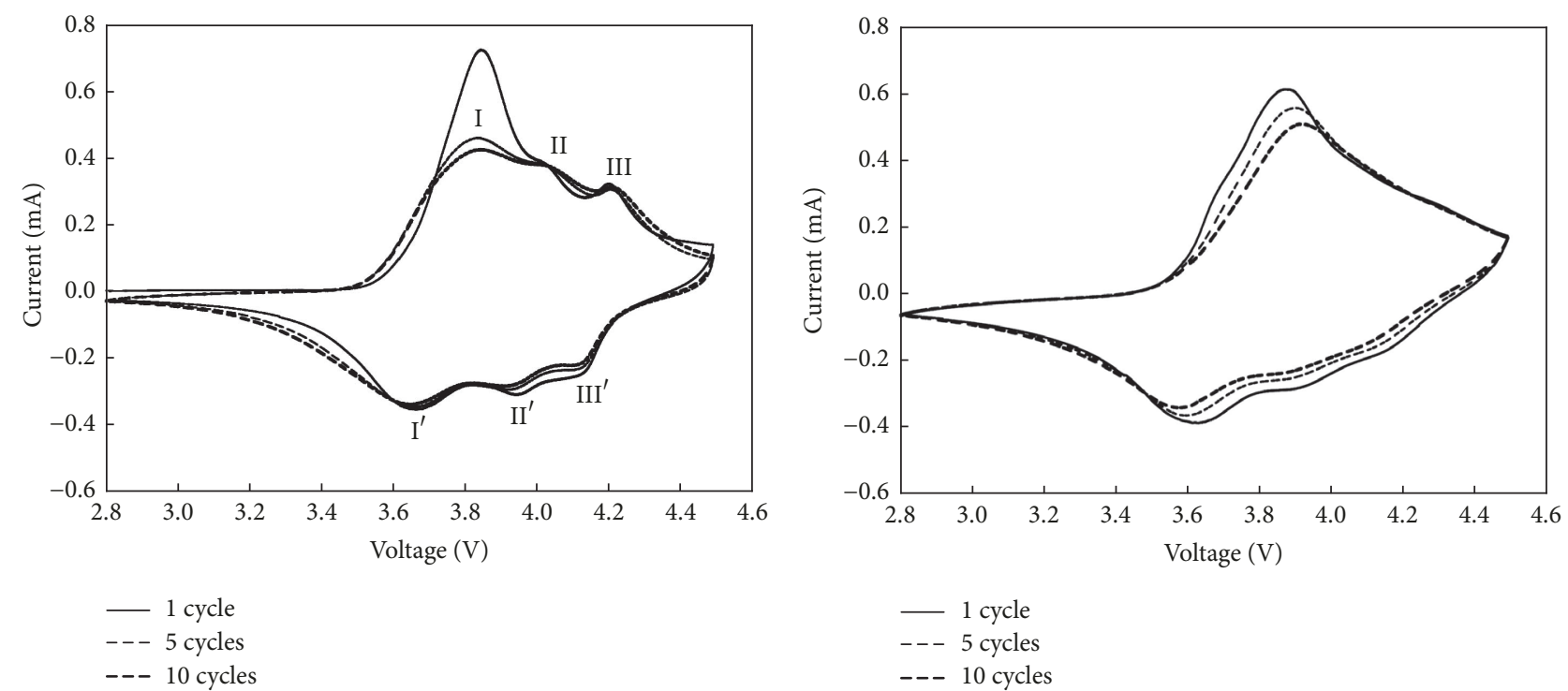

(a)

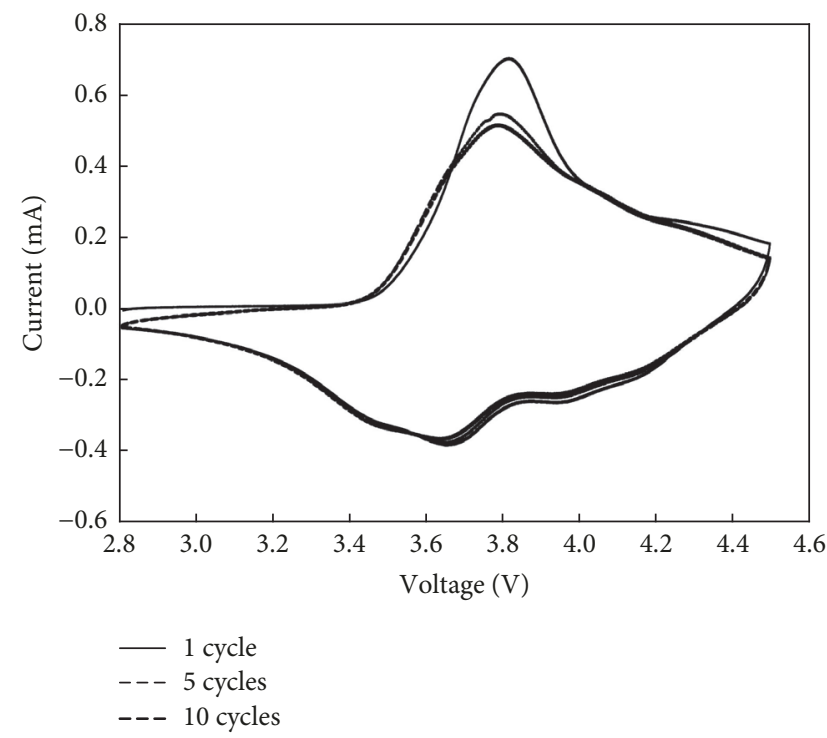

(c)

(b)

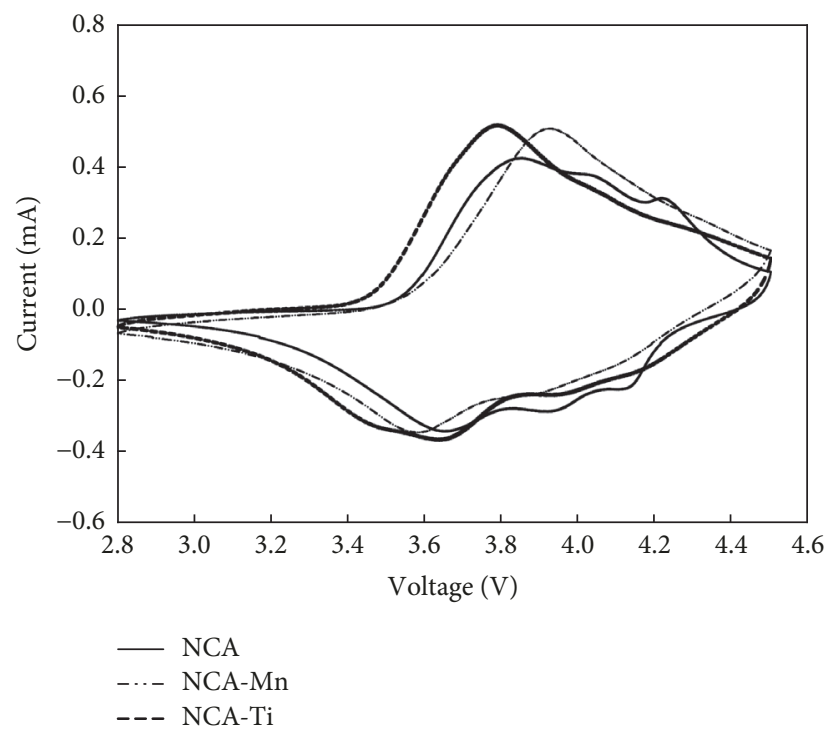

(d)

Figure 5: Cyclic voltammetry (CV) curves of (a) NCA, (b) NCA-Mn, (c) NCA-Ti electrodes, and (d) CV curves of different electrodes at 10 cycles.

The initial charge-discharge curves of the NCA, NCA$\mathrm{Mn}$, and NCA-Ti cathodes are shown in Figure 6(a). The charge-discharge test is performed in the voltage range $3.0-4.3 \mathrm{~V}$ at a rate of $0.1 \mathrm{C}$. The first discharge capacities of NCA, NCA-Mn, and NCA-Ti are 156.5, 171.4, and $179.6 \mathrm{mAh} \mathrm{g}^{-1}$, and the first charge capacities are 197.1, 209.9, and $202.6 \mathrm{mAh} \mathrm{g}^{-1}$, with initial coulombic efficiencies of $79.4 \%, 81.7 \%$, and $88.6 \%$, respectively. Studies have shown that the coulombic efficiency of NCA cathode is closely related to the interfacial resistance, which can be reduced significantly by metal doping $[30,31]$. The cycle performances of NCA, NCA-Mn, and NCA-Ti are shown in Figure 6(b). The discharge capacity of NCA is lower than that of metal-doped NCA-Mn or NCA-Ti. The best discharge capacity is found for the NCA-Ti because $\mathrm{Ti}^{4+}$ is introduced into the octahedral lattice space occupied by $\mathrm{Li}^{+}$to expand the $\mathrm{Li}$ layer spacing; thereby the $\mathrm{Li}^{+}$diffusion kinetics are improved. The discharge capacities of NCA, NCA-Mn, and NCA-Ti at the end of 30 cycles are $150.1,162.9$, and $166.7 \mathrm{mAh} \mathrm{g}^{-1}$, respectively. Better electrochemical performance of NCA-Ti is closely related to its excellent crystallization, layered structure, and electrical conductivity from the aforementioned analysis.

To investigate the variation in surface morphology of the different electrodes after 10 cycles, cross-sectional FESEM analysis was performed, as depicted in Figure 7. Figures $7(\mathrm{a})-7$ (c) show the fresh NCA, NCA-Mn, and NCA-Ti electrodes, while Figures $7(\mathrm{~d})-7(\mathrm{f})$ depict the same NCA, NCA-Mn, and NCA-Ti electrodes after the 10th discharge, 


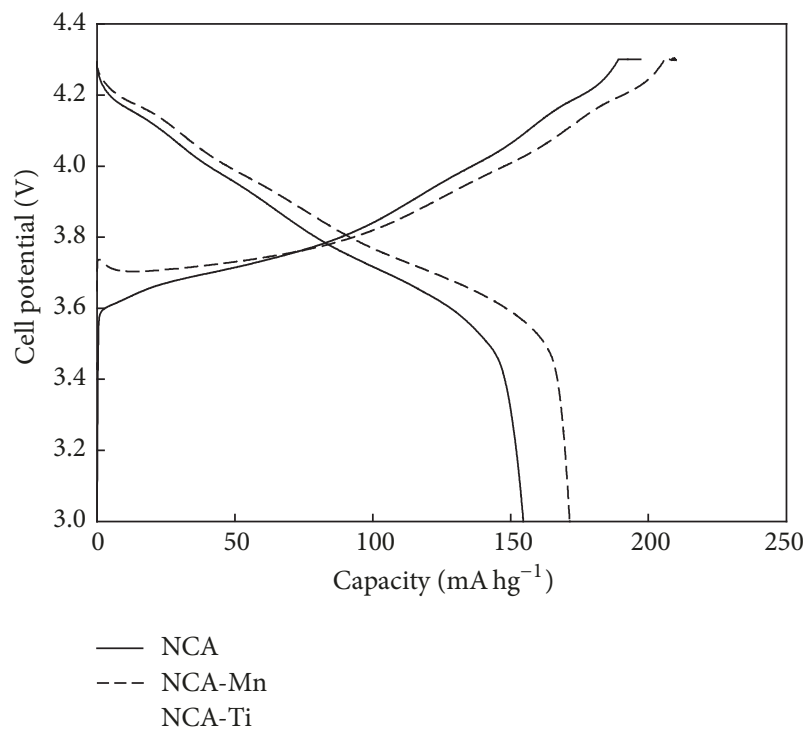

(a)

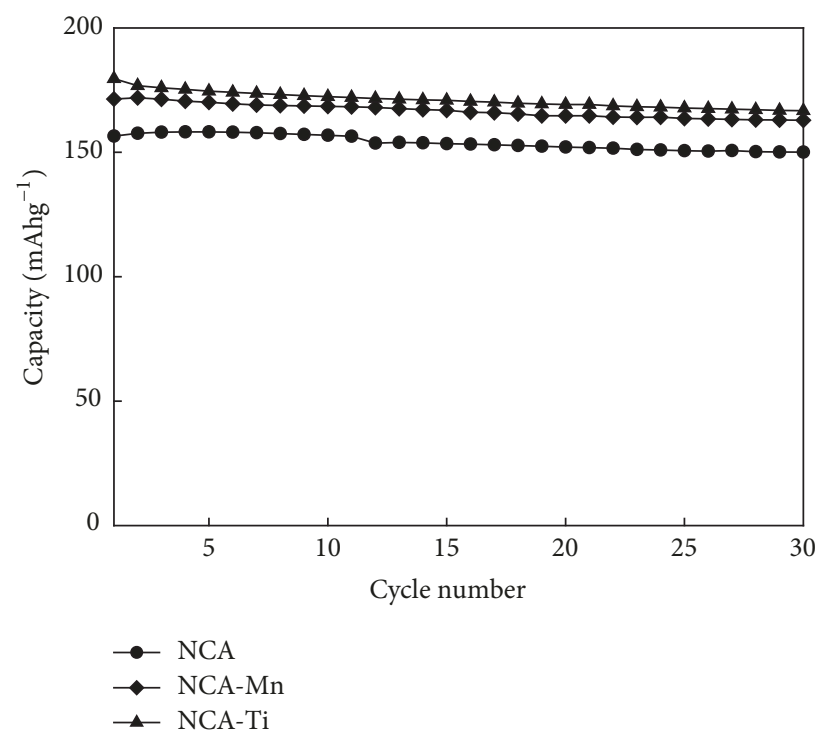

(b)

Figure 6: (a) Charge-discharge profiles at first cycle and (b) cycling performance of NCA, NCA-Mn, and NCA-Ti electrodes in a voltage range of 3.0 to $4.3 \mathrm{~V}$ at $0.1 \mathrm{C}$.

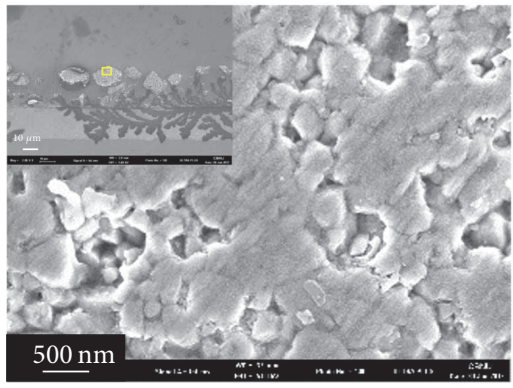

(a)

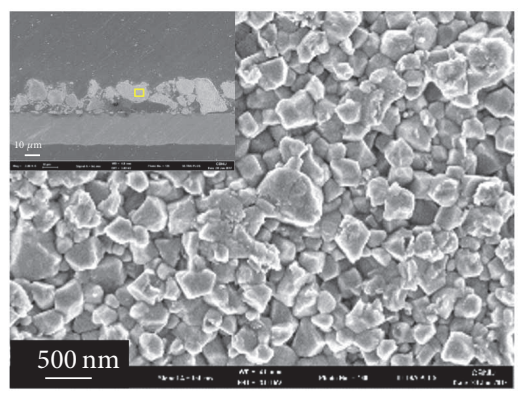

(d)

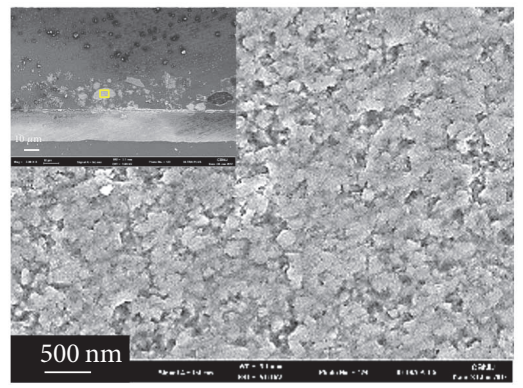

(b)

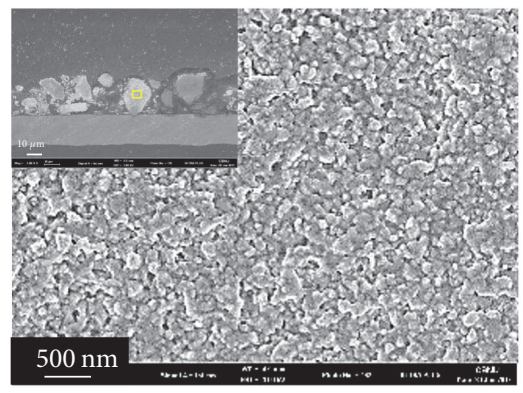

(e)

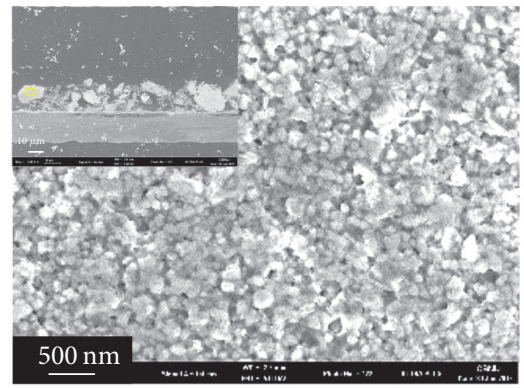

(c)

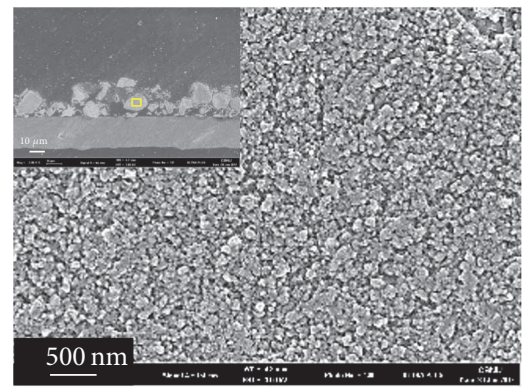

(f)

FiguRE 7: Enlarged cross-sectional FE-SEM images of (a)-(c) fresh electrodes and (d)-(f) after discharging 10 cycles of (a), (d) for NCA, (b), (e) for NCA-Mn, and (c), (f) for NCA-Ti electrodes. The inset images are low magnification FE-SEM images of each electrode.

respectively. The insertion figures in Figure 7 show the enlarged images for the rectangular part of the cross-sectional images of the electrodes. As can be seen in the crosssectional FE-SEM images, the electrodes show clear change after cycling when compared with the fresh electrodes. The larger primary particle size of NCA is found after 10th cycle discharged compared to before cycling. However, the NCA$\mathrm{Mn}$ and NCA-Ti are almost unchanged even after cycling.
This suggests that the NCA-Mn and NCA-Ti electrodes have a stable structure with much less structural change during cycling. Thus, the electrochemical properties of NCA can be improved by doping with $\mathrm{Mn}$ or Ti.

Nyquist plots of the fresh NCA, NCA-Mn, and NCATi electrodes and the electrodes after the 10th cycle are shown in Figure 8. Experimental results shown in solid lines are fitted by the equivalent circuit in the inset of Figure 8 


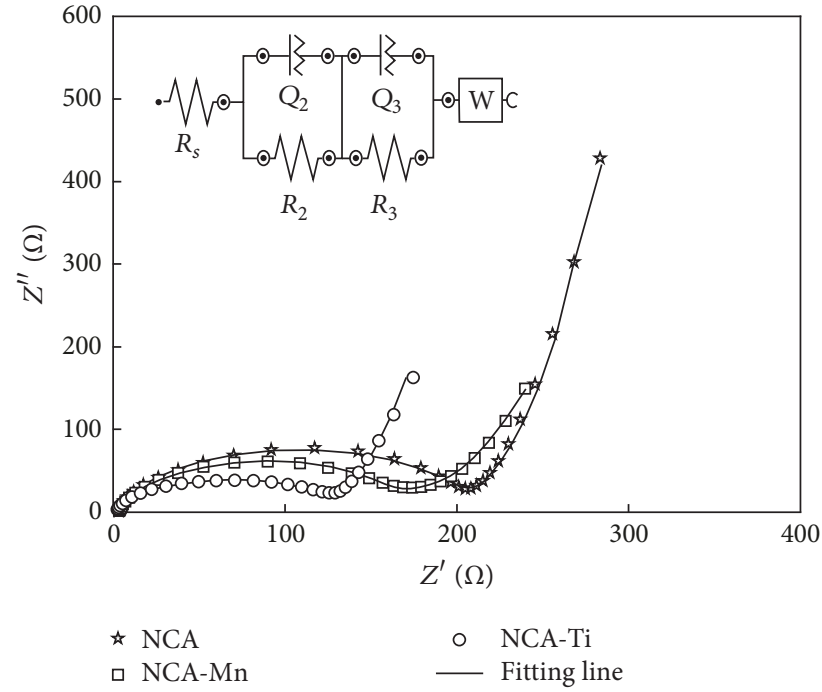

(a)

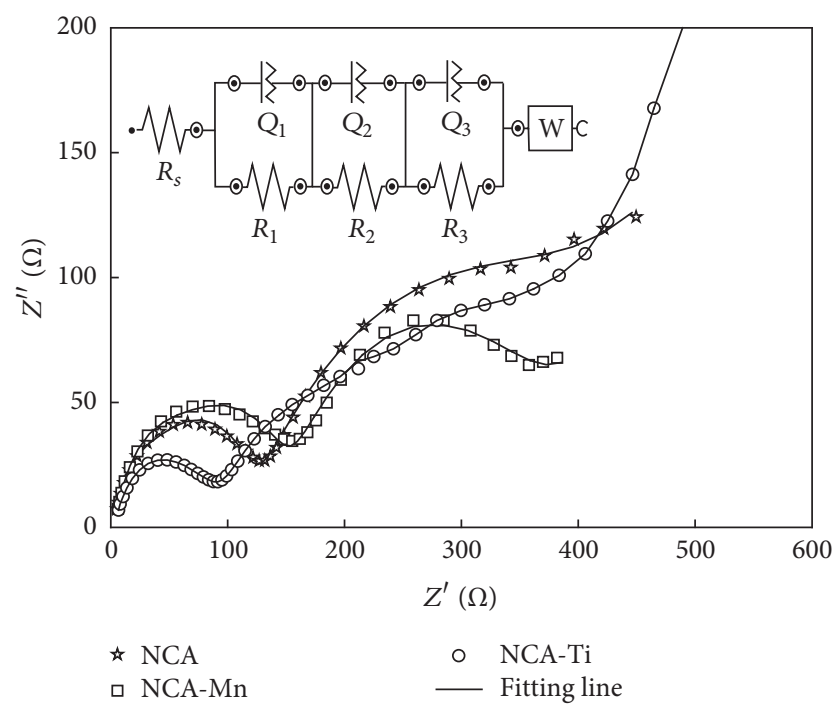

(b)

FIgURE 8: EIS analysis of NCA, NCA-Mn, and NCA-Ti electrode (a) before cycling and (b) after 10 cycles discharged.

TABLE 2: EIS results of lithium ion batteries with NCA, NCA-Mn, and NCA-Ti electrodes.

\begin{tabular}{|c|c|c|c|c|}
\hline Samples & $R_{1}(\Omega)$ & $R_{2}(\Omega)$ & $R_{3}(\Omega)$ & $R_{s}(\Omega)$ \\
\hline \multicolumn{5}{|l|}{ Fresh } \\
\hline NCA & - & 34.8 & 157.1 & 3.0 \\
\hline NCA-Mn & - & 29.0 & 130.2 & 2.0 \\
\hline NCA-Ti & - & 29.2 & 95.0 & 1.5 \\
\hline \multicolumn{5}{|c|}{ After 10th discharging } \\
\hline NCA & 31.1 & 80.5 & 277.4 & 5.1 \\
\hline NCA-Mn & 52.4 & 90.2 & 210.6 & 5.3 \\
\hline NCA-Ti & 24.2 & 48.7 & 189.7 & 6.1 \\
\hline
\end{tabular}

using the NOVA program (Version 1.10.4, Metrohm Autolab B.V.). Constant phase elements (CPEs) describing nonideal capacitances with parameters $\mathrm{Q}$ analogous to capacitance and the ideality factor $n$ are necessitated due to the existence of spatial and chemical nonuniformity across the electrode as well as the solid electrolyte interphase (SEI) surface. The inclined line at lower frequencies indicates the Warburg impedance (W), which represents the lithium ion diffusion process within the electrodes and $R_{s}$ is the solution resistance [32-36]. The Nyquist plots exhibit identical electrochemical behaviors with semicircles in the high-frequency region and a straight sloping line at low frequencies. The semicircle in the high-to-medium frequency region is related to the solid/electrolyte interphase (SEI) layer resistance $\left(R_{1}\right)$, and the semicircle at medium frequency is related to the charge transfer resistance $\left(R_{c t}=R_{2}+R_{3}\right)$. The EIS data for various electrodes used in LIBs are listed in Table 2. $R_{s}$ for all electrodes are increased after 10th discharging because of continuous SEI formation on the surface of the particles $[34,35]$. The $R_{\mathrm{ct}}$ values of the LIBs with the fresh NCA, NCA-Mn, and NCA-Ti electrodes are 191.9, 159.2, and $124.2 \Omega$, respectively, while the corresponding values after 10 cycles are 357.9, 300.8, and 238.4 $\Omega$. Moreover, it can be observed that the NCA-Ti electrode has the smallest SEI film resistance
$\left(R_{1}\right)$. This suggests that the NCA-Ti electrode has superior electrochemical properties and allows for rapid electron transport during the electrochemical $\mathrm{Li}^{+}$insertion/extraction reaction $[32,33]$. The EIS results agree well with the electrical conductivity (Figure 4(b)) and discharge behavior (Figure 6).

\section{Conclusions}

NCA cathode materials were successfully prepared by a hydrothermal reaction, and their electrochemical properties were improved by doping with the transition metals Mn and Ti. In particular, the Ti-doped cathode material (NCA-Ti) had a good crystalline structure and showed higher electrical conductivity than the other sample materials. In addition, the NCA-Ti electrode exhibited enhanced electrochemical performance. NCA-Ti showed the best discharge capacity of $179.6 \mathrm{mAh} \mathrm{g}^{-1}$ after the first cycle and an initial coulombic efficiency of $88.6 \%$.

\section{Conflicts of Interest}

The authors declare that there are no conflicts of interest regarding the publication of this paper. 


\section{Acknowledgments}

This work was funded by the MOTIE/KIAT [R0004144, development of high energy density cathode materials for discharge capacity $215 \mathrm{mAh} / \mathrm{g}$ or more]. Also, this research was supported by Basic Science Research Program through the National Research Foundation of Korea (NRF) funded by the Ministry of Education (2017R1D1A1B03028311).

\section{References}

[1] Y. Fu and A. Manthiram, "Core-shell structured sulfurpolypyrrole composite cathodes for lithium-sulfur batteries," RSC Advances, vol. 2, pp. 5927-5929, 2012.

[2] M. S. Whittingham, "Lithium batteries and cathode materials," Chemical Review, vol. 10, pp. 4271-4302, 2004.

[3] N. Leifer, O. Srur-Lavi, I. Matlahov, B. Markovsky, D. Aurbach, and G. Goobes, " $\mathrm{LiNi}_{0.8} \mathrm{Co}_{0.15} \mathrm{Al}_{0.05} \mathrm{O} 2$ Cathode material: new Insights via ${ }^{7} \mathrm{Li}$ and ${ }^{27} \mathrm{Al}$ magic-angle spinning NMR spectroscopy," Chemistry of Materials, vol. 28, no. 21, pp. 7594-7604, 2016.

[4] E. M. Jin, G. E. Lee, B. K. Na, and S. M. Jeong, "Electrochemical properties of commercial NCA Cathode materials for high capacity of lithium ion battery," Korean Chemical Engineering Research, vol. 55, pp. 163-169, 2017.

[5] F. chipper, E. M. Erickson, C. Erk, J. Y. Shin, F. F. Chesneau, and D. Aurbacha, "Review-recent advances and remaining challenges for lithium ion battery CathodesI. Nickel-Rich, $\mathrm{LiNi}_{x} \mathrm{Co}_{y} \mathrm{Mn}_{z} \mathrm{O}_{2}$," Journal of The Electrochemical Society, vol. 164, no. 1, pp. A6220-A6228, 2017.

[6] D. L. Vu and J. W. Lee, "Properties of $\mathrm{LiNi}_{0.8} \mathrm{Co}_{0.1} \mathrm{Mn}_{0.1} \mathrm{O}_{2}$ as a high energy cathode material for lithium-ion batteries," Korean Journal of Chemical Engineering, vol. 33, no. 2, pp. 514-526, 2016.

[7] J. Y. Lee, S. H. Shin, and S. H. Moon, "Flame retardant coated polyolefin separators for the safety of lithium ion batteries," Korean Journal of Chemical Engineering, vol. 33, pp. 285-289, 2016.

[8] S. H. Park, K. S. Park, Y. K. Sun, K. S. Nahm, Y. S. Lee, and M. Yoshio, "Structural and electrochemical characterization of lithium excess and Al-doped nickel oxides synthesized by the sol-gel method," Electrochimica Acta, vol. 46, pp. 1215-1222, 2001.

[9] X. Li, Z. Xie, W. Liu, W. Ge, H. Wang, and M. Qu, "Effects of fluorine doping on structure, surface chemistry, and electrochemical performance of $\mathrm{LiNi}_{0.8} \mathrm{Co}_{0.15} \mathrm{Al}_{0.05} \mathrm{O}_{2}$," Electrochimica Acta, vol. 174, pp. 1122-1130, 2015.

[10] B. Huang, X. Li, Z. Wang et al., "Enhanced electrochemical performance in $\mathrm{LiNi}_{0.8} \mathrm{Co}_{0.15} \mathrm{Al}_{0.05} \mathrm{O}_{2}$ cathode material: Resulting from $\mathrm{Mn}$-surface-modification using a facile oxidizing-coating method," Materials Letters, vol. 115, pp. 49-52, 2014.

[11] S. U. Woo, C. S. Yoon, K. Amine, I. Belharouak, and Y. K. Sun, "Significant Improvement of Electrochemical Performance of $\mathrm{AlF}_{3}$-Coated $\mathrm{Li}\left[\mathrm{Ni}_{0.8} \mathrm{Co}_{0.1} \mathrm{Mn}_{0.1}\right] \mathrm{O}_{2}$ Cathode Materials," Journal of The Electrochemical Society, vol. 154, pp. A1005A1009, 2007.

[12] Y. Chen, Q. Jiao, L. Wang et al., "Synthesis and characterization of $\mathrm{Li}_{1.05} \mathrm{Co}_{1 / 3} \mathrm{Ni}_{1 / 3} \mathrm{Mn}_{1 / 3} \mathrm{O}_{1.95} \mathrm{X}_{0.05}(\mathrm{X}=\mathrm{Cl}, \mathrm{Br})$ cathode materials for lithium-ion battery," Comptes Rendus Chimie, vol. 16, pp. 845-849, 2013.

[13] W. Luo, F. Zhou, X. Zhao, Z. Lu, X. Li, and J. R. Dahn, "Synthesis, Characterization, and Thermal Stability of
$\mathrm{LiNi}_{1 / 3} \mathrm{Mn}_{1 / 3} \mathrm{Co}_{1 / 3-z}-\mathrm{Mg}_{z} \mathrm{O}_{2}, \mathrm{LiNi}_{1 / 3-z} \mathrm{Mn}_{1 / 3} \mathrm{Co}_{1 / 3} \mathrm{Mg}_{z} \mathrm{O}$, and $\mathrm{LiNi}_{1 / 3} \mathrm{Mn1} / 3-\mathrm{zCol} / 3 \mathrm{MgzO}_{2}$," Chemistry of Materials, vol. 22, pp. 1164-1172, 2010.

[14] P. Yue, Z. Wang, X. Li et al., "The enhanced electrochemical performance of $\mathrm{LiNi}_{0.6} \mathrm{Co}_{0.2} \mathrm{Mn}_{0.2} \mathrm{O}_{2}$ cathode materials by low temperature fluorine substitution," Electrochimica Acta, vol. 95, pp. 112-118, 2013.

[15] B. Huang, X. Lin, Z. Wang, H. Guo, and X. Xiong, "Synthesis of Mg-doped $\mathrm{LiNi}_{0.8} \mathrm{Co}_{0.15} \mathrm{Al}_{0.05} \mathrm{O}_{2}$ oxide and its electrochemical behavior in high-voltage lithium-ion batteries," Ceramics International, vol. 40, pp. 13223-13230, 2014.

[16] W. Hua, J. Zhang, Z. Zheng et al., "Na-doped Ni-rich $\mathrm{LiNi}_{0.5} \mathrm{Co}_{0.2} \mathrm{Mn}_{0.3} \mathrm{O}_{2}$ cathode material with both high rate capability and high tap density for lithium ion batteries," Dalton Transactions, vol. 43, pp. 14824-14832, 2014.

[17] M. N. Ates, Q. Jia, A. Shah, A. Busnaina, S. Mukerjee, and K. M. Abraham, "Mitigation of layered to spinel conversion of a LiRich Layered metal oxide cathode material for Li-Ion batteries," Journal of The Electrochemical Society, vol. 161, no. 3, pp. A301A301, 2014.

[18] Z. Q. Deng and A. Manthiram, "Influence of Cationic Substitutions on the Oxygen Loss and Reversible Capacity of LithiumRich Layered Oxide Cathodes," Journal of Physical Chemistry C, vol. 115, no. 14, pp. 7097-7103, 2011.

[19] H. Chen, J. A. Dawson, and J. H. Harding, "Effects of cationic substitution on structural defects in layered cathode materials $\mathrm{LiNiO}_{2}$," Journal of Materials Chemistry A, vol. 2, pp. 79887996, 2014.

[20] B. Huang, X. Li, Z. Wang, and H. Guo, "A facile process for coating amorphous $\mathrm{FePO}_{4}$ onto $\mathrm{LiNi}_{0.8} \mathrm{Co}_{0.15} \mathrm{Al}_{0.05} \mathrm{O}_{2}$ and the effects on its electrochemical," Materials Letters, vol. 131, pp. 210-213, 2014.

[21] C. T. Hsieh, H. H. Hsu, J. P. Hsu, Y. F. Chen, and J. K. Chang, "Infrared-assisted synthesis of lithium nickel cobalt alumina oxide powders as electrode material for lithium-ion batteries," Electrochimica Acta, vol. 206, pp. 207-216, 2016.

[22] S. Myung, S. Komaba, K. Hosoya, N. Hirosaki, Y. Miura, and N. Kumagai, "Synthesis of $\mathrm{LiNi}_{0.5} \mathrm{Mn}_{0.5-x} \mathrm{Ti}_{x} \mathrm{O}_{2}$ by an Emulsion Drying Method and Effect of Ti on Structure and Electrochemical Properties," Chemistry of Materials, vol. 17, no. 9, pp. 2427-2435, 2005.

[23] T. Ohzuku, A. Ueda, and M. Nagayama, "Electrochemistry and Structural Chemistry of $\mathrm{LiNiO}_{2}(R \overline{3} m)$ for 4 Volt Secondary Lithium Cells," Journal of The Electrochemical Society, vol. 140, pp. 1862-1870, 1993.

[24] G. T. K. Fey, J. G. Chen, V. Subramanian, and T. Osaka, "Preparation and electrochemical properties of $\mathrm{Zn}$-doped $\mathrm{LiNi}_{0.8} \mathrm{Co}_{0.2} \mathrm{O}_{2}$," Journal of Power Sources, vol. 112, pp. 384-394, 2002.

[25] G. X. Wang, S. Zhong, D. H. Bradhurst, S. C. Dou, and H. K. Liu, "Synthesis and characterization of $\mathrm{LiNiO}_{2}$ compounds as cathodes for rechargeable lithium batteries," Journal of Power Sources, vol. 76, pp. 141-146, 1998.

[26] T. Ohzuku, A. Ueda, M. Nagayama, Y. Iwakoshi, and H. Komori, "Comparative study of $\mathrm{LiCoO}_{2}, \mathrm{LiNi}_{12} \mathrm{Co}_{12} \mathrm{O}_{2}$ and $\mathrm{LiNiO}_{2}$ for 4 volt secondary lithium cells," Electrochimica Acta, vol. 38, no. 9, pp. 1159-1167, 1993.

[27] D. Aurbach, K. Gamolsky, B. Markovsky et al., "Study of surface phenomena related to electrochemical lithium intercalation into $\mathrm{Li}_{x} \mathrm{MO}_{y}$ host materials $(\mathrm{M}=\mathrm{Ni}, \mathrm{Mn})$," Journal of The Electrochemical Society, vol. 147, no. 4, pp. 1322-1331, 2000. 
[28] Y. Zhang, Z. B. Wang, J. Lei et al., "Investigation on performance of $\mathrm{Li}\left(\mathrm{Ni}_{0.5} \mathrm{Co}_{0.2} \mathrm{Mn}_{0.3}\right)_{1-x} \mathrm{Ti}_{x} \mathrm{O}_{2}$ cathode materials for lithiumion battery," Ceramics International, vol. 41, pp. 9069-9077, 2015.

[29] H. Xie, K. Du, G. Hu, Z. Peng, and Y. Cao, "The Role of Sodium in $\mathrm{LiNi}_{0.8} \mathrm{Co}_{0.15} \mathrm{Al}_{0.05} \mathrm{O}_{2}$ Cathode Material and Its Electrochemical Behaviors," Journal of Physical Chemistry C, vol. 120, pp. 3236-3241, 2016.

[30] H. Kondo, Y. Takeuchi, T. Sasaki et al., "Effects of Mgsubstitution in $\mathrm{Li}(\mathrm{Ni}, \mathrm{Co}, \mathrm{Al}) \mathrm{O} 2$ positive electrode materials on the crystal structure and battery performance," Journal of Power Sources, vol. 174, no. 2, pp. 1131-1136, 2007.

[31] X. Li, F. Kang, W. Shen, and X. Bai, "Improvement of structural stability and electrochemical activity of a cathode material $\mathrm{LiNi}_{0.7} \mathrm{Co}_{0.3} \mathrm{O}_{2}$ by chlorine doping," Electrochimica Acta, vol. 53, pp. 1761-1765, 2007.

[32] C. H. Chen, J. Liu, M. E. Stoll, G. Henriksen, D. R. Vissers, and K. Amine, "Aluminum-doped lithium nickel cobalt oxide electrodes for high-power lithium-ion batteries," Journal of Power Sources, vol. 128, no. 2, pp. 278-285, 2004.

[33] G. Peng, X. Yao, H. Wan et al., "Journal of Power Sources," Insights on the fundamental lithium storage behavior of allsolid-state lithium batteries containing the $\mathrm{LiNi}_{0.8} \mathrm{Co}_{0.15} \mathrm{Al}_{0.05} \mathrm{O}_{2}$ cathode and sulfide electrolyte, vol. 307, pp. 724-730, 2016.

[34] G. Qian, L. Wang, Y. Shang et al., "Polyimide binder: a facile way to improve safety of lithium ion batteries," Electrochimica Acta, vol. 187, pp. 113-118, 2016.

[35] Q. C. Zhuang, X. Y. Qiu, S. D. Xu, Y. H. Qiang, and S. G. Sun, Diagnosis of Electrochemical Impedance Spectroscopy in LithiumIon Batteries. Chapter 8, 2012.

[36] J. Huang, Z. Li, H. Ge, and J. Zhang, "Analytical solution to the impedance of electrode/electrolyte interface in lithium-ion batteries," Journal of The Electrochemical Society, vol. 162, pp. A7037-A7048, 2015 


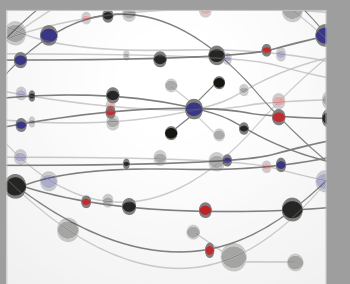

The Scientific World Journal
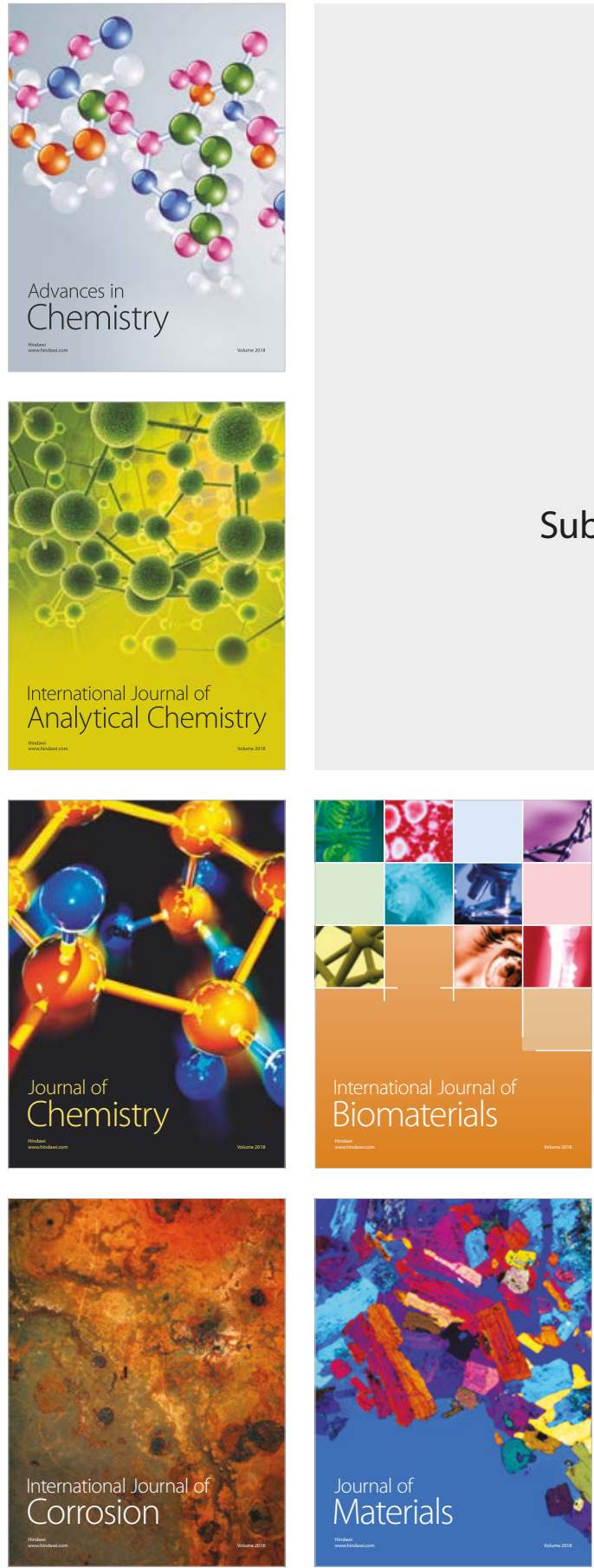

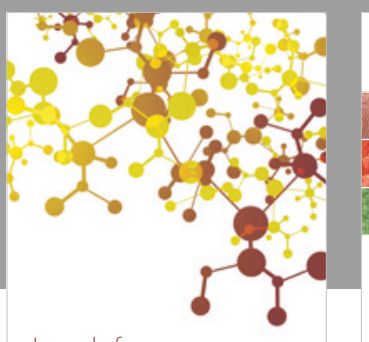

Journal of

Applied Chemistry
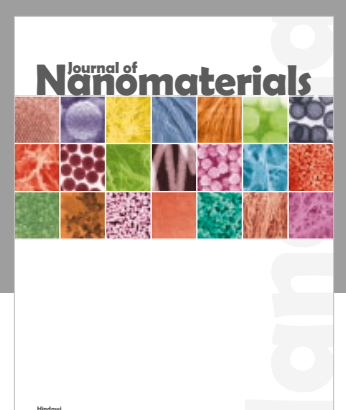

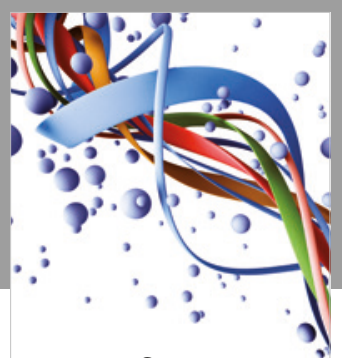

Scientifica

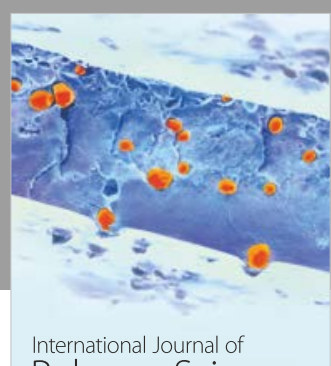

Polymer Science

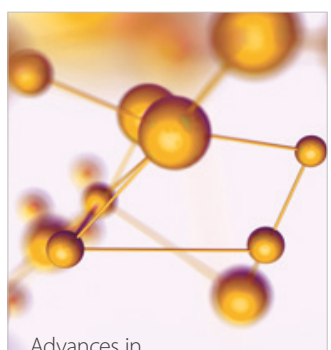

Physical Chemistry
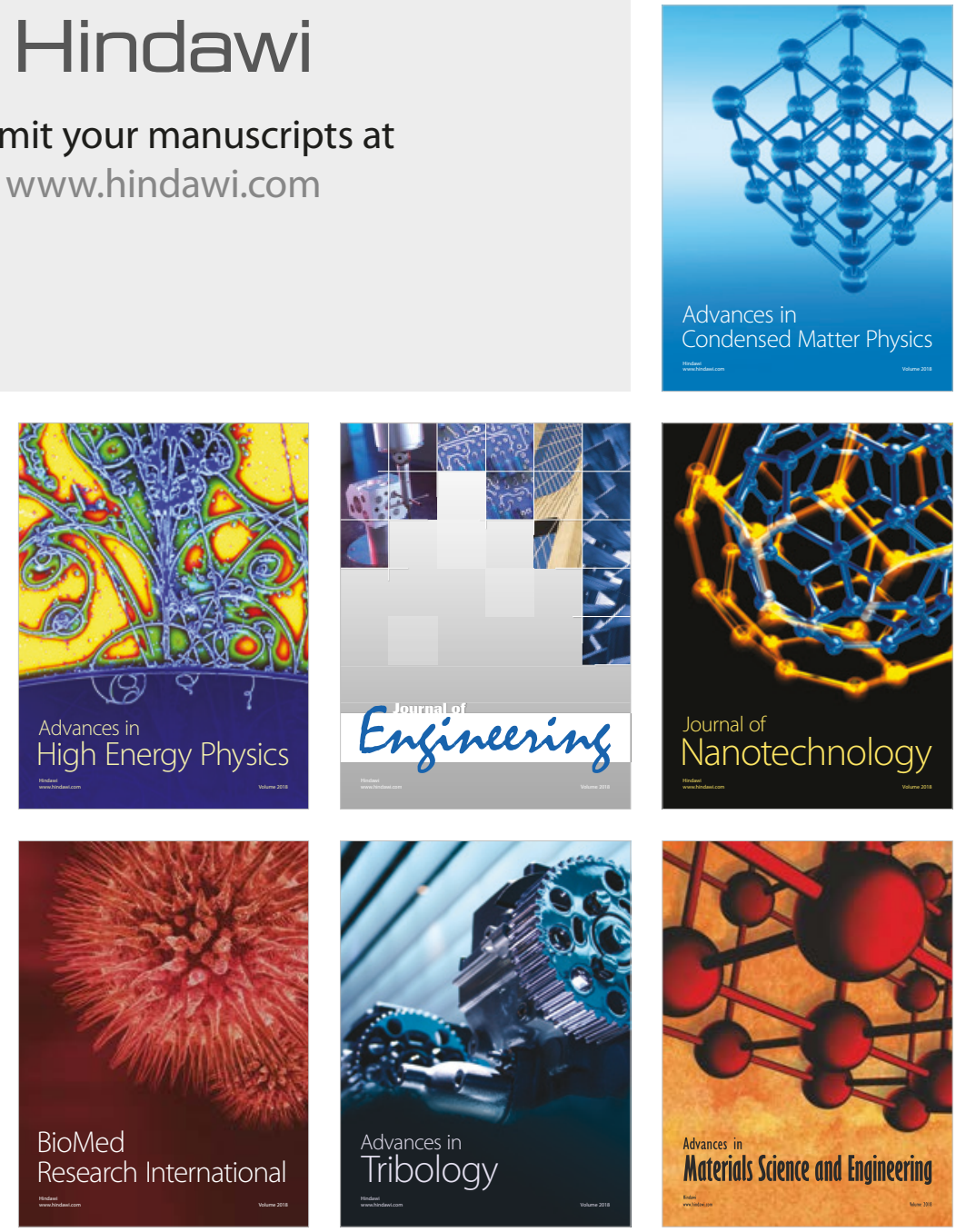